\title{
Evolution of Liver Transplant Selection Criteria and U.S. Allocation Policy for Patients with Hepatocellular Carcinoma
}

\author{
Julie K. Heimbach, MD ${ }^{1}$ \\ ${ }^{1}$ Department of Transplant Surgery, William J. von Liebig Transplant \\ Center, Mayo Clinic College of Medicine, Rochester, Minnesota \\ Semin Liver Dis 2020;40:358-364.
}

Address for correspondence Julie Heimbach, MD, Department of Transplant Surgery, Mayo Clinic College of Medicine, 200 First Street SW, Rochester, MN 55905 (e-mail: heimbach.julie@mayo.edu).

\author{
Abstract \\ Keywords \\ - liver transplantation \\ - hepatocellular \\ carcinoma \\ - HCC \\ - allocation
}

Liver transplantation (LT) is an optimal treatment option for early-stage unresectable hepatocellular carcinoma (HCC) in patients with cirrhosis as it provides a treatment for underlying liver disease as well as a decreased incidence of recurrent cancer compared with alternative treatment strategies. A primary barrier to LT for HCC is the critical shortage of available liver allografts. The system of prioritization and access to deceased donor transplantation for patient with HCC in the United States has continued to evolve, while variable approaches including no additional priority, are in use around the world. While the Milan criteria remain the most well-established pretransplantation selection criteria, multiple other algorithms which expand beyond Milan have been proposed. The current review focuses on liver allocation for HCC as well as the principles and varied models available for pretransplant patient selection.
The incidence of hepatocellular carcinoma (HCC) is increasing worldwide, and is now the fifth most common tumor and the third most common cause of cancer mortality. ${ }^{1}$ In the United States, mortality for HCC has increased faster than for any other tumor primarily due to cirrhosis from hepatitis $C$ virus as well as other etiologies such as alcohol, nonalcoholic fatty liver disease, and hepatitis B virus. ${ }^{2,3}$ The increased incidence of HCC combined with the demonstrated efficacy of liver transplantation (LT) for HCC treatment and a favorable allocation policy have led to HCC being the most common indication for LT in the United States. ${ }^{4}$

This dramatic rise in transplantation for HCC is particularly remarkable considering that the early experience with LT for HCC produced such uniformly dismal results that in 1989 the Department of Health and Human Services listed HCC as a contraindication for LT. ${ }^{5,6}$ The initial unfavorable outcomes of LT in the setting of HCC led to the conclusion that LT was not suitable as a treatment for HCC, though this was largely due to the use of LT as a "last resort" only for those with very extensive tumors. Patients undergoing LT for other indications who were found to have incidental tumors demonstrated excellent survival rates, suggesting that patients with limited tumor burden may benefit from LT. The landmark publication from Mazzaferro et al in 1996 demonstrated 83\% recurrence-free survival and $75 \%$ actuarial survival at 4 years for patients undergoing LT for HCC within specific criteria, clearly defining the essential role of patient selection. ${ }^{7}$

Due to these encouraging findings as well as validation from other reports, ${ }^{7-9}$ LT was once again approved in the U.S. as a treatment option for patients with HCC, though access to transplantation for patients with HCC was significantly limited by the national organ allocation system, which prior to 2002 was based on waiting time and medical status. Since that time, the field of HCC has evolved to include the option of living donor LT (LDLT) for adults beginning in 1998, the adoption of the Model for End-Stage Liver Disease (MELD)based organ allocation system, as well as advancements in liver-directed therapies used as a bridge to transplantation or as primary therapy, and the approval of modestly effective systemic therapies for advanced HCC.

Importantly, in the U.S. from 2000 to 2002 , HCC was one of the most common indications for LDLT as there was no other viable option. However, while the use of LDLT for treatment of patients with HCC has continued to flourish around the published online

September 17, 2020
Copyright $\odot 2020$ by Thieme Medical Publishers, Inc., 333 Seventh Avenue, New York, NY 10001, USA. Tel: +1(212) 760-0888.
DOI https://doi.org/ 10.1055/s-0040-1709492. ISSN 0272-8087. 
world, most notably in Asia, the combination of a widely published donor death and the adoption of the MELD system in 2002, which included an overprioritization for HCC patients, led to a marked reduction in the use of LDLT for HCC patients in the United States. Initial concern of an increased risk of HCC recurrence in the setting of LDLT for HCC have instead been determined to be related to patient selection, and perhaps related to changes in organ allocation policy as well as the ongoing critical organ shortage. LDLT is once again rising in the U.S. both for patients with and without HCC.

\section{Evolution of Allocation Policy for Patients with HCC}

The MELD-based system for allocation of deceased donor livers was adopted in the United States in 2002, and has been associated with a decrease in waitlist mortality and an increase in post-LT survival. ${ }^{10,11}$ This system was updated to include sodium in 2016, which has led to a further decrease in waitlist mortality without any impact on postLT survival ${ }^{12,13}$ Patients with HCC as well as other complications of cirrhosis and certain metabolic conditions have an increased mortality risk (without access to timely LT) which is not predicted by their calculated MELD or MELD-Na score. Therefore, they are allowed to receive assigned MELD scores (commonly referred to as MELD exception scores). Since inception, the MELD system has continued to evolve through multiple revisions as summarized in - Fig. 1.

The process of awarding exception scores for HCC in the United States is automated for patients whose tumors are within designated criteria. Historically, assigned MELD score exceptions started at a score intended to reflect a 15\% risk of waitlist drop out over a 3-month period, and this score increased every 3 months by a value anticipated to reflect a 10\% increased risk of mortality without transplantation. The initial scores of 24 for T1 and 28 for T2 were reduced twice as they awarded too much priority to HCC patients, relative to non-HCC patients. ${ }^{14,15}$ Until very recently, patients who presented with HCC beyond Milan criteria who were successfully downstaged by liver-directed therapy had to undergo an appeals process to a review board.

While this system of MELD score exceptions allowed access to LT for patients with HCC, several important issues arose. First, despite the two early downward adjustments of the initial assigned score, except in parts of the United States with the longest wait times, patients with HCC exception scores still had a markedly higher transplant rate and a significantly lower waitlist dropout rate than nonexception patients, leading to a major disparity in access to transplant between patients in the U.S. with and without HCC. ${ }^{16-18}$ Second, it was noted that the median MELD score at the time of transplant continued to rise yearly in nearly every area of the country, and this "MELD inflation" was hypothesized to be related to the system of

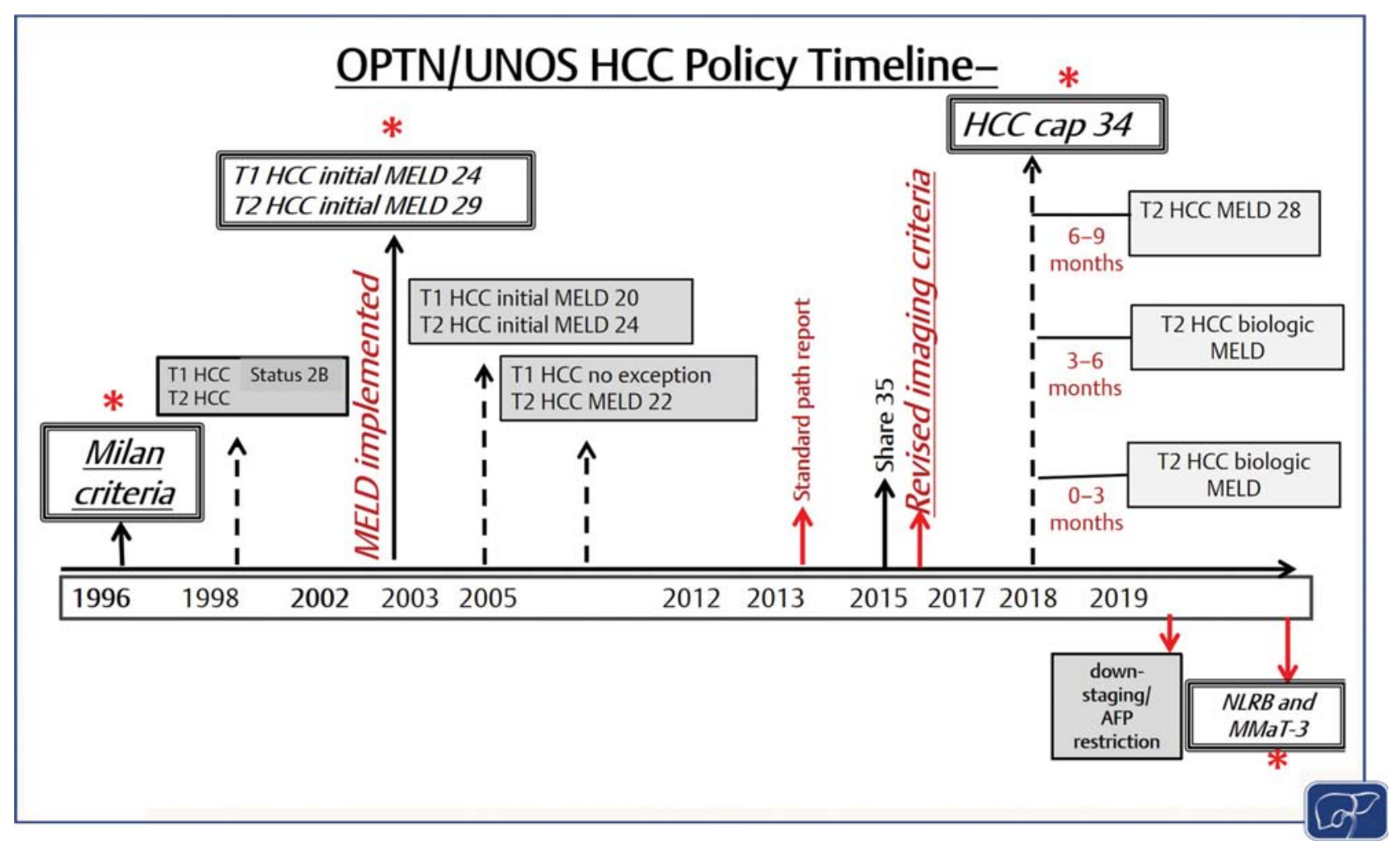

Fig. 1 U.S. liver selection and allocation policy changes for hepatocellular carcinoma over time. ${ }^{*}$ Changes which have had the most significant impact. T1/T2: T1 a single tumor 1-2 cm, and T2 1-2 tumors between 1 and $3 \mathrm{~cm}$ or 1 tumor $2-5 \mathrm{~cm}$. Share 35 : a change which shared liver allografts across the regions for candidates with a Model for End-Stage Liver Disease (MELD) score of 35 and higher, before being offered to candidates within the local area. AFP, $\alpha$-fetoprotein. NLRB, National Liver Review Board. MMaT-3, median MELD at Transplant-3 which refers to the score awarded for hepatocellular carcinoma (HCC) patients under the new review board and is a score adjusted according to the median score required to access transplant in the area where the patient is waiting. 
exception scores which created large concentrations of relatively stable patients at specific score thresholds reflective of the exception scores granted for patients every 3 months (22, $25,28,29$, etc.). ${ }^{19}$ Finally, it was noted that the regional review system was highly inconsistent in the approach to patients with HCC outside of standard criteria, as well as for patients with other non-policy-based MELD exception requests. ${ }^{20}$ These issues were some of the most important challenges to the U.S. system.

\section{Balancing Access for HCC and Non-HCC Patients}

The issue of unequal access to LT for HCC and non-HCC patients is of particular importance given that this disparity is primarily a result of organ allocation policy. This differs from the critical shortage in available deceased donor organs overall, which relates a shortage of donors relative to the number of potential recipients. Allocation policy in the United States begins with the organ-specific committees of the Organ Procurement and Transplantation Network (OPTN), which are made up of volunteer representatives of the transplant community from around the country, and after an extensive process of statistical modeling, gathering public feedback, and subsequent revision, the final policy is ultimately determined by the governing board of the OPTN, which is also made up of representatives of the transplant community as well as the public.

The overprioritization for HCC patients was addressed by the "cap and delay" policy revision, which after favorable modeling, was adopted in $2015 .^{21}$ This revision added a 6month waiting period before patients could be transplanted based on their assigned HCC exception score, though the score granted after 6 months was MELD 28 (the same as they would have had after waiting 6 months under the prior system). This avoided further disadvantaging patients waiting in high MELD regions, yet allowed for biologic selection by essentially mimicking what was already happening in the higher MELD areas where the transplant rates between HCC and non-HCC patients were noted to be more similar. By prolonging the waiting time, tumors with poor biology will be identified and futile transplantation may be reduced, as supported by an analysis of U.S. data by Halazun et al demonstrating worse outcomes for HCC patients transplanted in U.S. regions with very short waiting times compared with regions with long wait times. ${ }^{22} \mathrm{~A}$ recent analysis of transplant rates for HCC and non-HCC patients in the U.S. in the 2 years just prior to and just after the policy change determined that HCC candidates had a 37\% lower risk of waitlist mortality/dropout prepolicy and a comparable risk of mortality/dropout postpolicy, and concluded that the revised policy established equity between HCC and nonHCC waitlist candidates. ${ }^{23}$

\section{Improved Standardization for HCC Exception Patients} Addressing the issues of MELD inflation and inconsistent approaches by regional review boards for HCC and non-HCC patients required a more significant change. First, a national policy to address patients who initially presented with HCC beyond the Milan criteria but who were successfully down- sized to within Milan criteria was implemented in December of 2017. This change adopted the downstaging criteria initially proposed by University of California San Francisco (UCSF) to define the allowable tumor burden prior to downstaging treatment ( 1 lesion between 5 and $8 \mathrm{~cm}, 2-3$ lesions with at least one greater than $3 \mathrm{~cm}$ though none greater than $5 \mathrm{~cm}$ and sum of all less than $8 \mathrm{~cm}, 4-5$ lesions all less than $3 \mathrm{~cm}$ and sum less than $8 \mathrm{~cm}$ ), as well as a cap on the maximum $\alpha$-fetoprotein (AFP) at $1,000 \mathrm{ng} / \mathrm{mL}$, creating a consistent national downstaging policy for these patients. Both changes were adopted to factor biologic behavior in the prediction of both waitlist and post-LT outcomes.

Second, in May of 2019, a National Liver Review Board (NLRB) was adopted, changing the regional review board system of exception review to a national review system. The main goal was to improve consistency around the U.S., making things more equitable for patients and addressing concerns that some areas had more liberal acceptance of non-policy-based exception requests. A secondary purpose was to improve efficiency. The newly adopted NLRB has three distinct boards, including one specifically to handle HCC exception requests which do not meet policy criteria. Guidance documents addressing the most common non-policybased exception requests were created for all three boards to provide criteria to guide the board and centers when considering or preparing non-policy-based exception requests.

To address the conundrum of how to set a national score in the setting of marked regional differences in the score required to access transplant across the U.S., as well as concern over the previously described "MELD inflation," a fixed score set 3 points below the median score required to access transplantation in the area of distribution where the candidate is listed (MMaT-3) was adopted with the adoption of the NLRB. The new exception score does not increase every 3 months, but remains a fixed score, so that allocation for exception patients relies on time waiting with approved exception. This is in contrast to the prior elevator system which also relied heavily on time waiting, but allowed patients with exceptions to be transplanted at a significantly higher rate than non-exception patients as previously noted. The median MELD is recalculated every 6 months using the previous 12 months of data and scores are subsequently adjusted. The primary goal of the use of MMaT is to assign a score that is adjusted based on the score required to access transplant in the area where the patient is waiting, given there are differences around the U.S. in the median score required to access to transplant, while secondary goals are to continue to address overprioritization of HCC patients (though this may have been largely addressed by the cap and delay policy adopted in 2015) and to ameliorate MELD inflation. While data on how this system may perform is not yet available, based on modeling, it is anticipated that this may lead to at least stabilization of the median MELD score and potentially a decrease, as well as standardize the approach to exception patients. Importantly, similar to prior policy changes, it is possible that further adjustments to the assigned score of MMaT -3 (either lower or higher) may be needed to achieve better parity with nonexception patients. 
Table 1 U.S. selection and allocation for HCC in 2020

\begin{tabular}{|l|}
\hline Selection for automatic exception score: \\
\hline - AFP $<1,000 \mathrm{ng} / \mathrm{mL}$. If AFP $\geq 1,000 \mathrm{ng} / \mathrm{mL}$, it must fall \\
below $500 \mathrm{ng} / \mathrm{mL}$ after treatment and \\
remain $<500 \mathrm{ng} / \mathrm{mL}$ \\
\hline AND \\
\hline - Patients within Milan criteria: $1-2$ tumors between 1 and \\
$3 \mathrm{~cm}$, or 1 tumor between 2 and $5 \mathrm{~cm}$ \\
\hline OR \\
\hline - Downstaged to Milan criteria by liver-directed therapy \\
from initial downstaging criteria: 1 tumor between 5 and \\
$8 \mathrm{~cm}, 2-3$ none greater than $5 \mathrm{~cm}$ and sum $<8 \mathrm{~cm}, 4-5$ \\
lesions all less than 3 cm and sum $<8$ cm \\
\hline Awarded MELD exception score: \\
\hline - MMaT-3. After 6 -month wait, patients are awarded a fixed \\
score of 3 points lower than Median MELD at Transplan- \\
tation (MMaT-3) for patients transplanted within the area \\
of distribution where the candidate is listed (distribution is \\
a concentric circle model as of February 4,2020 .) MMaT is \\
recalculated every 6 months based on the previous 1 year of \\
data
\end{tabular}

Abbreviations: AFP, $\alpha$-fetoprotein; HCC, hepatocellular carcinoma; MELD, Model for End-Stage Liver Disease.

The current system for HCC patient selection and organ allocation is summarized in - Table $\mathbf{1}$.

In addition to the major changes impacting patient selection and organ allocation policy for HCC highlighted earlier, more modest but still important policy changes have also occurred as noted in - Fig. 1. The adoption of a standardized pathology form provided required elements including the size, location, number, and grade of HCC lesions found in the explant which are reported using a standardized format, which allows for improved documentation and interpretation as well as data which can be used to guide future policy revision. Adoption of standardized imaging criteria to ensure centers were following a minimum acceptable standard for the noninvasive diagnosis of HCC was also necessary to ensure that patients had findings that would justify additional waitlist prioritization.

Other options for addressing access to transplantation for patients with HCC have been adopted around the world. For example, in the U.K., a benefit model was adopted in 2018 which gives priority to urgent cases as well as to those with the highest anticipated benefit from transplant based on a formula combining multiple donor and recipient parameters, including the recipient diagnosis of HCC. ${ }^{24}$ The Transplant Benefit concept ranks candidates by combining the principles of both urgency and utility. Importantly, the period of time over which benefit is measured will impact the allocation, as a longer time will favor younger candidates and a shorter time will favor older candidates, provided they have a higher waitlist mortality. There are also considerable challenges to the identification of pretransplant factors beyond age which may reliably predict long-term posttransplant outcome, and thus, the model adopted by the U.K. will surely provide valuable guidance and insight into the feasibility of a more widespread adoption of a benefit-based system. ${ }^{25}$ Euro-transplant utilizes a MELD-based system with additional exception points awarded for HCC and increased every 90 days; Italy uses a MELD-based system with additional HCC points at the time of listing, while France uses a system which incorporates AFP and requires HCC treatment. ${ }^{26,27}$ While a thorough discussion of the evolution of HCC allocation around the world is beyond the scope of the review, it is essential to know that there are multiple approaches utilized by countries around the world with varied degrees of overlap, each typically relying on the assessment of tumor biology by the use of tumor size, number of nodules, biomarkers, or/and response to therapy with perhaps the one common theme being all systems require ongoing monitoring and revision.

\section{Selection Criteria for Liver Transplantation for HCC}

Just as the system for allocation of livers for patients with HCC has evolved, so too has the criteria by which patients with HCC are selected, and the most common selection criteria are summarized in -Table 2. As described above, in the U.S. those presenting within the Milan criteria as well as those who are initially outside of Milan but who undergo successful downstaging to within Milan are eligible for an assigned MELD exception score and access to deceased donor transplantation. This modest expansion beyond the Milan criteria was based on the observation that excellent outcomes can be achieved with LT for HCC both for those within Milan and for a subset of patients beyond Milan criteria. One of the earliest to be developed is the UCSF criteria, in which patients with a single lesion up to $6.5 \mathrm{~cm}$, or up to 3 lesions none greater than 4.5 and a total tumor burden $<8 \mathrm{~cm}$ were demonstrated to have outcomes equivalent to those within the Milan criteria, with approximately $80 \%$ survival at 5 years, though another reports from centers outside of UCSF have not had as favorable results. ${ }^{28,29}$

In addition to the Milan and UCSF criteria, several other systems have been proposed for pretransplant selection for patients with HCC (see - Table 2). The overall principal underlying the drive for expanded criteria is well-captured by the "Metroticket" concept, again by the group in Milan, which recognizes that transplanting patients with more advanced tumors does impact posttransplant outcome, in a stepwise and potentially predictable way such that "price" that is paid in terms of HCC recurrence and inferior outcomes or reduced access to transplantation for other non-HCC patients is proportionate to how far beyond standard HCC selection criteria the system is willing to go (the up-to-seven criteria-the sum of the largest tumor in $\mathrm{cm}$ plus the number of tumors is $\leq 7) .{ }^{30}$ The recently published Metroticket 2.0 uses a model based on level of AFP, tumor size, and tumor number 
Table 2 Liver transplant selection criteria used for patients with HCC (adopted from Santopaolo et al) ${ }^{37}$

\begin{tabular}{|c|c|c|c|}
\hline Selection system & $\begin{array}{l}\text { Year } \\
\text { proposed }\end{array}$ & Criteria & Pros/cons \\
\hline Milan criteria & 1996 & $\begin{array}{l}\text { Single nodule }<5 \mathrm{~cm} \text { or up to } 3 \text { lesions } \\
\text { none larger than } 3 \mathrm{~cm} \text {, no macrovascular } \\
\text { invasion }\end{array}$ & $\begin{array}{l}\text { Gold-standard. Allows for excellent post-LT } \\
\text { outcomes, but may limits access for some } \\
\text { beyond criteria who may do well }\end{array}$ \\
\hline UCSF criteria & 2007 & $\begin{array}{l}\text { Single nodule up to } 6.5 \mathrm{~cm} \text { or up to } 3 \\
\text { lesions, the largest is } 4.5 \mathrm{~cm} \text { and total sum } \\
\text { of all diameters is }<8 \mathrm{~cm}\end{array}$ & $\begin{array}{l}\text { Improves access for patients beyond Milan, } \\
\text { with excellent reported outcomes. Lower } \\
\text { survival reported by other centers using } \\
\text { these criteria }\end{array}$ \\
\hline Up-to-seven criteria & 2009 & $\begin{array}{l}\text { Sum in size of largest tumor plus total } \\
\text { number of tumors is }<7\end{array}$ & $\begin{array}{l}\text { Multicenter, and easy to understand. Has } \\
\text { not been adopted, lower outcomes than } \\
\text { UCSF }\end{array}$ \\
\hline $\begin{array}{l}\text { Total tumor volume } \\
\text { and AFP criteria }\end{array}$ & 2009 & $\begin{array}{l}\text { Total tumor volume }<115 \mathrm{~cm}^{3} \text { and } \\
\text { AFP }<400 \mathrm{ng} / \mathrm{mL} \text {, without macrovascular } \\
\text { invasion or extrahepatic metastasis }\end{array}$ & $\begin{array}{l}\text { Includes biologic component reflected by } \\
\text { AFP. Not widely adopted to date }\end{array}$ \\
\hline Kyoto criteria & 2013 & $\begin{array}{l}<10 \text { tumors; }<5 \mathrm{~cm} \text { and des-gamma car- } \\
\text { boxy-prothrombin }<400 \mathrm{mAU} / \mathrm{mL}\end{array}$ & $\begin{array}{l}\text { Excellent survival at } 5 \text { years, low recur- } \\
\text { rence; not widely used or validated outside } \\
\text { Asia }\end{array}$ \\
\hline $\begin{array}{l}\text { Extended Toronto } \\
\text { criteria }\end{array}$ & 2016 & $\begin{array}{l}\text { Any size or number of tumors, without } \\
\text { systemic cancer related symptom, extra- } \\
\text { hepatic disease, macrovascular invasion, } \\
\text { or poorly differentiated histology based on } \\
\text { biopsy of largest lesion }\end{array}$ & $\begin{array}{l}\text { Allows broader access with slight impact } \\
\text { on survival, but higher recurrence rate, } \\
\text { requires biopsy, and includes subjective } \\
\text { components }\end{array}$ \\
\hline HALT-HCC & 2017 & AFP, MELD, and total tumor burden & $\begin{array}{l}\text { Includes biologic component and consid- } \\
\text { ers underlying liver disease }\end{array}$ \\
\hline
\end{tabular}

Abbreviations: AFP, $\alpha$-fetoprotein; HALT-HCC, Hazard Associated with Liver Transplantation for Hepatocellular Carcinoma; HCC, hepatocellular carcinoma; LT, liver transplantation; UCSF, University of California San Francisco.

which was intended to achieve at least $70 \%$ tumor-specific 5-year survival. For patients with an AFP $<200 \mathrm{ng} / \mathrm{mL}$, the sum of the number of tumors and size in $\mathrm{cm}$ should be less than 7 , while for AFP 200 to $400 \mathrm{ng} / \mathrm{mL}$, the sum of tumor number plus size should be $\leq 5$, and if the level of AFP is 400 to $1,000 \mathrm{ng} / \mathrm{mL}$, the sum of the number and size of tumors should be $\leq 4$. This model was developed with multi-institution data from Italy and validated in a population from China. ${ }^{31}$

Other proposed systems also use a biologic component to the score, and generally, the size of the largest lesion is the component with the strongest prognostic role. Toso et al proposed a system using a population of HCC patients from Canada and Switzerland based on total tumor volume $<115 \mathrm{~cm}^{3}$ and AFP $<400 \mathrm{ng} / \mathrm{mL}$, while French have proposed and validated in Italy a system including AFP, as well as number and size of nodules, with each variable being assigned a specific number of points between 0 and 4, and those with 2 or less points being considered low-risk. ${ }^{32,33}$ The primary difference of these two models compared with either the Milan criteria or the UCSF criteria is the use of AFP, which was independently predictive of worse outcomes even for patients within Milan criteria. A continuous risk score, Hazard Associated with Liver Transplantation for HCC has also been developed and validated in an international cohort, and includes AFP and tumor burden, plus MELD-Na, and they have recently published a larger application. ${ }^{34}$ The Kyoto criteria include a restriction on total number of tumors $(\leq 10)$ as well as size of the largest tumor $(\leq 5 \mathrm{~cm})$ and des-gamma-carboxy-prothrombin $<400 \mathrm{mAU} / \mathrm{mL}$, and for those within these criteria, a remarkably low recurrence rate of just $4 \%$ at 5 years is reported though the number meeting these criteria in this study was just 147 out of a total of $198 .{ }^{35}$ Recently, investigators have also proposed the use of machine learning decision tree techniques to optimize selection criteria both for HCC and non-HCC patients based on a large number of variables for waitlisted and transplanted patients already collected in OPTN data from 2002 to 2016 to develop more accurate prediction of 3-month risk of waitlist dropout due to death or becoming unsuitable for transplantation. Perhaps not surprisingly, the same variables of tumor number, size, and AFP are also part of this system. ${ }^{36}$

\section{Conclusion and Future Directions}

While the advantages of LT for HCC include excellent long-term disease-free survival as well as treatment of underlying cirrhosis, a primary disadvantage especially for patients who do not have a potential living donor option, is the critical shortage of available deceased organs, leading for the need for an allocation system as well as the need to carefully select which HCC patients are most likely to benefit from transplantation. Regardless of whether the system is a MELD-based system with exceptions for patients with HCC within specific criteria as in the U.S., or a different system, there will be need to balance the risk of disease progression and potential for waitlist drop out for both HCC and non-HCC patients. The most essential step for the future following any organ allocation or distribution policy change is an objective, efficient, and collaborative effort by the transplant community to optimize 
the new system. The most recent changes in the U.S. have been significant both for HCC and non-HCC patients and will require additional and likely ongoing revision such as adjusting the size of the distribution circles according to population density, or determining whether MMaT-3 is the optimal prioritization for HCC, or if it should be raised or lowered. It would be ideal if updated analysis tools could be developed, potentially using artificial intelligence or machine learning to facilitate such efforts. If instead of optimizing the newly developed system, the community is instead directed to embark on the development of an entirely new system, such as the borderless allocation model, in addition to the risk of further discord within the transplant community, there is also a risk that patients will be subjected to a nonoptimized allocation system for a prolonged period while a new system is developed.

\section{Conflicts of Interest}

None declared.

\section{References}

1 World Health Organization. Liver fact sheets. Available at: http:// gco.iarc.fr/today/data/factsheets/cancers/11-Liver-fact-sheet.pdf. Accessed March 16, 2020

2 White DL, Thrift AP, Kanwal F, Davila J, El-Serag HB. Incidence of hepatocellular carcinoma in all 50 United States, from 2000 through 2012. Gastroenterology 2017;152(04):812-820.e5

3 Singal AG, El-Serag HB. Hepatocellular carcinoma from epidemiology to prevention: translating knowledge into practice. Clin Gastroenterol Hepatol 2015;13(12):2140-2151

4 Yang JD, Larson JJ, Watt KD, et al. Hepatocellular carcinoma is the most common indication for liver transplantation and placement on the waitlist in the United States. Clin Gastroenterol Hepatol 2017;15(05):767-775.e3

5 Iwatsuki S, Starzl TE, Sheahan DG, et al. Hepatic resection versus transplantation for hepatocellular carcinoma. Ann Surg 1991;214 (03):221-228, discussion 228-229

6 Ringe B, Pichlmayr R, Wittekind C, Tusch G. Surgical treatment of hepatocellular carcinoma: experience with liver resection and transplantation in 198 patients. World J Surg 1991;15(02):270-285

7 Mazzaferro V, Regalia E, Doci R, et al. Liver transplantation for the treatment of small hepatocellular carcinomas in patients with cirrhosis. N Engl J Med 1996;334(11):693-699

8 Llovet JM, Bruix J, Fuster J, et al. Liver transplantation for small hepatocellular carcinoma: the tumor-node-metastasis classification does not have prognostic power. Hepatology 1998;27(06): 1572-1577

9 Figueras J, Jaurrieta E, Valls C, et al. Survival after liver transplantation in cirrhotic patients with and without hepatocellular carcinoma: a comparative study. Hepatology 1997;25(06): 1485-1489

10 Wiesner RH, McDiarmid SV, Kamath PS, et al. MELD and PELD: application of survival models to liver allocation. Liver Transpl 2001;7(07):567-580

11 Kamath PS, Kim WR; Advanced Liver Disease Study Group. The model for end-stage liver disease (MELD). Hepatology 2007;45 (03):797-805

12 Biggins SW, Kim WR, Terrault NA, et al. Evidence-based incorporation of serum sodium concentration into MELD. Gastroenterology 2006;130(06):1652-1660

13 Nagai S, Chau LC, Schilke RE, et al. Effects of allocating livers for transplantation based on model for end-stage liver disease-sodium scores on patient outcomes. Gastroenterology 2018;155(05): 1451-1462.e3
14 Wiesner RH, Freeman RB, Mulligan DC. Liver transplantation for hepatocellular cancer: the impact of the MELD allocation policy. Gastroenterology 2004;127(05, Suppl 1):S261-S267

15 Sharma P, Harper AM, Hernandez JL, et al. Reduced priority MELD score for hepatocellular carcinoma does not adversely impact candidate survival awaiting liver transplantation. Am J Transplant 2006;6(08):1957-1962

16 Freeman RB, Edwards EB, Harper AM. Waiting list removal rates among patients with chronic and malignant liver diseases. Am J Transplant 2006;6(06):1416-1421

17 Washburn K, Edwards E, Harper A, Freeman R. Hepatocellular carcinoma patients are advantaged in the current liver transplant allocation system. Am J Transplant 2010;10(07):1643-1648

18 Massie AB, Caffo B, Gentry SE, et al. MELD exceptions and rates of waiting list outcomes. Am J Transplant 2011;11(11):2362-2371

19 Northup PG, Intagliata NM, Shah NL, Pelletier SJ, Berg CL, Argo CK. Excess mortality on the liver transplant waiting list: unintended policy consequences and Model for End-Stage Liver Disease (MELD) inflation. Hepatology 2015;61(01):285-291

20 Gish RG, Wong RJ, Honerkamp-Smith G, Xu R, Osorio RW. United Network for Organ Sharing regional variations in appeal denial rates with non-standard Model for End-Stage Liver Disease/Pediatric End-Stage Liver Disease exceptions: support for a national review board. Clin Transplant 2015;29(06):513-522

21 Heimbach JK, Hirose R, Stock PG, et al. Delayed hepatocellular carcinoma model for end-stage liver disease exception score improves disparity in access to liver transplant in the United States. Hepatology 2015;61(05):1643-1650

22 Halazun KJ, Patzer RE, Rana AA, et al. Standing the test of time: outcomes of a decade of prioritizing patients with hepatocellular carcinoma, results of the UNOS natural geographic experiment. Hepatology 2014;60(06):1957-1962

23 Ishaque T, Massie AB, Bowring MG, et al. Liver transplantation and waitlist mortality for HCC and non-HCC candidates following the 2015 HCC exception policy change. Am J Transplant 2019;19(02): 564-572

24 Tschuor C, Ferrarese A, Kuemmerli C, Dutkowski P, Burra P, Clavien PA; Liver Allocation Study Group. Allocation of liver grafts worldwide - is there a best system? J Hepatol 2019;71(04):707-718

25 Neuberger J, Heimbach JK. Allocation of deceased-donor livers - is there a most appropriate method? J Hepatol 2019;71(04): 654-656

26 European Association for the Study of the Liver. Electronic address: easloffice@easloffice.eu; European Association for the Study of the Liver. EASL Clinical Practice Guidelines: management of hepatocellular carcinoma. J Hepatol 2018;69(01):182-236

27 Notarpaolo A, Layese R, Magistri P, et al. Validation of the AFP model as a predictor of HCC recurrence in patients with viral hepatitis-related cirrhosis who had received a liver transplant for HCC. J Hepatol 2017;66(03):552-559

28 Yao FY, Ferrell L, Bass NM, et al. Liver transplantation for hepatocellular carcinoma: expansion of the tumor size limits does not adversely impact survival. Hepatology 2001;33(06):1394-1403

29 Yao FY, Xiao L, Bass NM, Kerlan R, Ascher NL, Roberts JP. Liver transplantation for hepatocellular carcinoma: validation of the UCSF-expanded criteria based on preoperative imaging. Am J Transplant 2007;7(11):2587-2596

30 Yao FY, Hirose R, LaBerge JM, et al. A prospective study on downstaging of hepatocellular carcinoma prior to liver transplantation. Liver Transpl 2005;11(12):1505-1514

31 Mazzaferro V, Llovet JM, Miceli R, et al; Metroticket Investigator Study Group. Predicting survival after liver transplantation in patients with hepatocellular carcinoma beyond the Milan criteria: a retrospective, exploratory analysis. Lancet Oncol 2009;10 (01):35-43

32 Mazzaferro V, Sposito C, Zhou J, et al. Metroticket 2.0 model for analysis of competing risks of death after liver transplantation for 
hepatocellular carcinoma. Gastroenterology 2018;154(01): 128-139

33 Sapisochin G, Goldaracena N, Laurence JM, et al. The extended Toronto criteria for liver transplantation in patients with hepatocellular carcinoma: a prospective validation study. Hepatology 2016;64(06):2077-2088

34 Toso C, Meeberg G, Hernandez-Alejandro R, et al. Total tumor volume and alpha-fetoprotein for selection of transplant candidates with hepatocellular carcinoma: a prospective validation. Hepatology 2015;62(01):158-165
35 Kaido T, Ogawa K, Mori A, et al. Usefulness of the Kyoto criteria as expanded selection criteria for liver transplantation for hepatocellular carcinoma. Surgery 2013;154(05):1053-1060

36 Bertsimas D, Kung J, Trichakis N, Wang Y, Hirose R, Vagefi PA. Development and validation of an optimized prediction of mortality for candidates awaiting liver transplantation. Am J Transplant 2019;19(04):1109-1118

37 Santopaolo F, Lenci I, Milana M, Manzia TM, Baiocchi L. Liver transplantation for hepatocellular carcinoma: Where do we stand? World J Gastroenterol 2019;25(21):2591-2602 